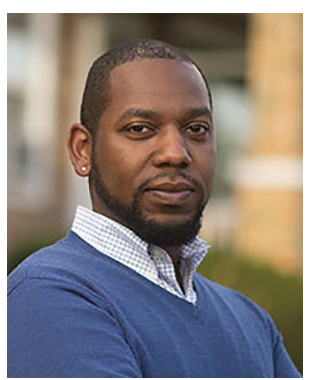

\title{
A call for authentic Black engagement in the academy and beyond
}

\author{
Efforts to eliminate anti-Black racism in academia must go far beyond superficial ticking of \\ boxes. The academic community must create conditions for authentic, not tokenistic, Black \\ engagement, argues Tony Reames.
}

Credit: Tony G. Reames

$\mathrm{D}$ uring the summer of 2020 , the streets of cities and towns across America, and even the world, filled with protesters demanding justice for the state-sanctioned murders of Black Americans, most recently George Floyd and Breonna Taylor. At the same time, many academic and academic-adjacent institutions, already reckoning with the fallout of a global pandemic, had to come to terms with how they would respond in this new moment of racial and social unrest. I and several of my friends, who also happen to be the lone or one of a few Black faculty members in our university departments, pondered what was different about this time and what did this moment require of us. Little did we know that we would bear the burden of helping our white colleagues and in some cases our entire schools and universities figure out the same.

Black faculty, students and staff are grossly underrepresented in higher education. Navigating academic spaces dominated by systems of white supremacy and oppression - while difficult for many Black faculty, students and staff-is our norm. Ours is a life of experiences operating within a system that was never designed for us to equally participate in.

In my own field of environmental studies, for example, the lack of Black representation is emblematic of a larger equity problem in the field as a whole and in environmental decision making. It represents a misconception of what the word environment even means and perpetuates a misunderstanding that Black people do not care about the environment, nature or the outdoors. It also reinforces the persistent environmental racism that propagates increased COVID-19 mortality in over-polluted Black communities, the absence of green space in urban Black communities, over-surveillance of Black bodies by the police and a sense of non-belonging by Black people in our own suburban neighborhoods.
Until there is recognition by those who inherently benefit from a system designed for some to excel and for others to fail, what we are witnessing during this moment of social unrest and reckoning will be for naught.

What this moment calls for is a devotion to a set of authentic and shared values by the body politic. What this is not is a moment for individuals and institutions to tick off a list of surface-level demonstrations that only accomplish an internal feeling of being anti-racist. Neither is this a moment for non-Black academics to take advantage of by launching new research projects on Black bodies and in Black communities, especially projects that are void of Black people authentically engaged in them. To engage in genuine anti-racist activities in the academy and beyond, I argue that the academic community must start by considering four points.

First, how does your research and teaching perpetuate colonialism and systemic and institutional racism? Are you actively seeking out Black scholars for collaboration? Do you cite Black scholars in your work or assign readings by Black scholars in your courses? You must diversify your curriculum. What perspectives and narratives are you not exposing your students to? Do you invite Black speakers as guest lecturers? It is totally acceptable to solicit student input and ask who and what they are reading or listening to.

Second, if and when you engage with Black faculty, students or communities, do not tokenize the engagement. Ask yourself: are they equal partners? Are they co-creators of knowledge? Are they being respected for the knowledge and lived experience they bring to the team? Most importantly, are they being equitably compensated? Uncompensated extraction from Black bodies and communities is inherent to the anti-Black racism long perpetuated in academia. Therefore, to move forward authentically, be intentional and transparent about both the mutual and non-mutual benefits of the engagement.

Third, how do or can you provide space, unique support and culturally relevant and responsive resources for Black students, faculty and staff? Do you recruit or mentor Black students, especially from communities in which you conduct research? Do you acknowledge the emotional labor required by your Black students and colleagues to experience frequent racial microaggressions in meetings, at conferences and in your lab? Are you even cognizant that these situations may exist?

Lastly, in America (and across the globe) we must stop pretending that anti-Black racism has somehow faded into human unconsciousness or that we have reached some post-racial precipice. As Boston Globe columnist Renée Graham wrote in June 2020, it is time to "Make America Uncomfortable Again." For nations, our universities, our workplaces, our healthcare system, even our environment to ever be great, we as a society must continuously be pushed in ways that make us uncomfortable. Otherwise, we will be unable to authentically confront and defeat the systemic anti-Black racism that so deeply corrupts our nations, schools, workplaces, healthcare system and environment.

Tony G. Reames ${ }^{凶}$

Urban Energy Justice Lab, University of Michigan School for Environment \& Sustainability, Ann Arbor, Michigan, USA.

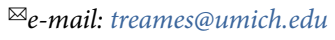

Published online: 26 October 2020

https://doi.org/10.1038/s41562-020-00984-8

\section{Acknowledgements}

This is an edited version of my comments during a 10 June 2020 virtual conversation entitled "Being an Environmentalist while Black" with my colleagues D. Taylor and B. Butt at the University of Michigan.

The author declares no competing interests. 